\title{
Intraductal Papilloma of Buccal Mucosa Minor Salivary Gland Origin
}

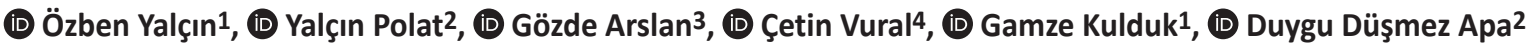 \\ 1 University of Health Sciences Turkey, İstanbul Okmeydanı Training and Research Hospital, Clinic of Pathology, Istanbul, Turkey \\ 2Biruni University Faculty of Medicine, Department of Pathology, Istanbul, Turkey \\ ${ }^{3}$ Maltepe University Faculty of Medicine, Department of Radiology, Istanbul, Turkey \\ ${ }^{4}$ Maltepe University Faculty of Medicine, Department of Otorhinolaryngology, Istanbul, Turkey
}

\section{Abstract}

Ductal papillomas are rarely seen in salivary glands. They are largely classified under the term "ductal papillomas" and generally further categorized as intraductal papilloma, sialadenoma papilliferum, and inverted ductal papilloma. Intraductal papilloma, which usually arises from the major lactiferous duct and localized in minor salivary glands, is an uncommon lesion. We report a case of intraductal papilloma of the buccal mucosa.

Keywords: Salivary glands, intraductal papilloma, benign

\section{INTRODUCTION}

Ductal papillomas are rarely seen in salivary glands. Ductal papillomas are benign papillary tumors and originate from the neoplastic proliferation of any epithelium of the ductal system. Intraductal papilloma is a rare lesion and mostly arises from the major lactiferous duct (1-3).

\section{CASE REPORT}

A 65-year-old male patient referred to the otolaryngology department with the complaint of a mass in the right cheek for 3 years. There was no pain. Head and neck examination revealed the presence of an easily noticeable mass in both skin and mucosal surfaces of the right cheek. Bi-manual examination showed a $4 \times 2 \mathrm{~cm}$ oval-shaped, firm, and mobile mass.

Under general anesthesia, via a buccal mucosal incision, the tumor was removed without any complication and sent to the pathology department.

\section{Radiologic Features}

The patient was referred to the radiology department for magnetic resonance (MR) exam. MR exam was performed with a 1.5-T system MR scanner (Intera, Philips Medical Systems, Best, The Netherlands). Axial, coronal, and sagittal T1 TSE -T2 TSE weighted images, axial T2 weighted SPIR images, diffusionweighted series, and post-contrast series were taken. Postcontrast images were acquired after administration $0.1 \mathrm{mmol} /$ $\mathrm{kg}$ gadolinium diethylenetriamine pentaacetic acid. On MR imaging, a 42×28x14 mm multilobulated, T1WS isointense, T2WS hyperintense, heterogeneous subcutaneous mass adjacent to right corpus mandibula (Figure 1a-b). Diffusion was restricted, and the lesion showed homogeneous contrast enhancement on contrast series (Figure 2). There was no mandibular bony defect. The lesion was excised, and the specimen was sent for histopathological evaluation.

Microscopic features (Figures 3,4): a dilated, unicystic structure was located below the mucosal surface. Cystic space was

Phone: +90 5052385350 E-mail: ozbena@yahoo.com ORCID ID: orcid.org/0000-0002-0019-1922

Cite this article as: Yalçın Ö, Polat Y, Arslan G, Vural Ç, Kulduk G, Düşmez Apa D. Intraductal Papilloma of Buccal Mucosa Minor Salivary Gland Origin. Eur Arch Med Res 2020; 36 (1):86-9

${ }^{\circ}$ Copyright 2020 by the University of Health Sciences Turkey, Okmeydanı Training and Research Hospital European Archives of Medical Research published by Galenos Publishing House. 
lined by two layers of cuboidal epithelium. Papillary growths protruded into the lumina. There was a branching and anastomosing pattern. Each papilla was composed of doublelayered columnar epithelial cells, with a fibrovascular core. The nuclei of the cells were basally located, and they had a monotonous appearance. No mitotic figures and no evidence of atypia were examined. The tumor cells were limited within the ductal space. There was no cellular proliferation beyond the cyst wall.

\section{Immunohistochemistry}

The tumor cells expressed pan-cytokeratin and epithelial membrane antigen but were negative for smooth muscle actin, and the Ki-67 labeling index was low.
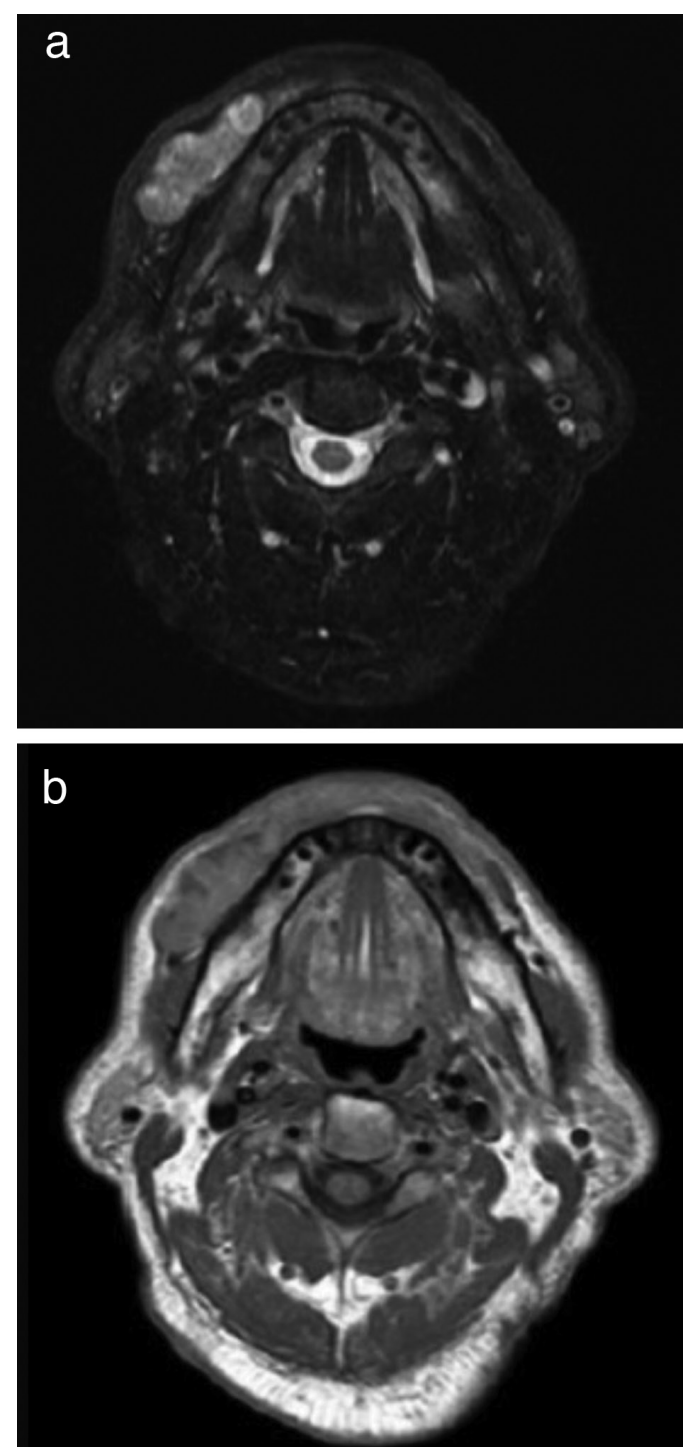

Figure 1. a, b) On MRI, a 42×28x14 mm multilobulated, T1WS (a) isointense, T2WS (b) hyperintense, heterogeneous subcutaneous mass adjacent to right corpus mandibula MRI: Magnetic resonance imaging

\section{DISCUSSION}

Benign papillary tumors confined to the ducts in salivary glands are rare and categorized under the term "ductal papillomas". These lesions further classified as three distinct types of tumors: intraductal papilloma, sialadenoma papilliferum, and inverted ductal papilloma $(1,2)$.

According to the literature, Brannon et al. (4) reported the largest survey with 19 cases about ductal papillomas in 2001. Three out of 19 cases were intraductal papillomas. They reviewed the

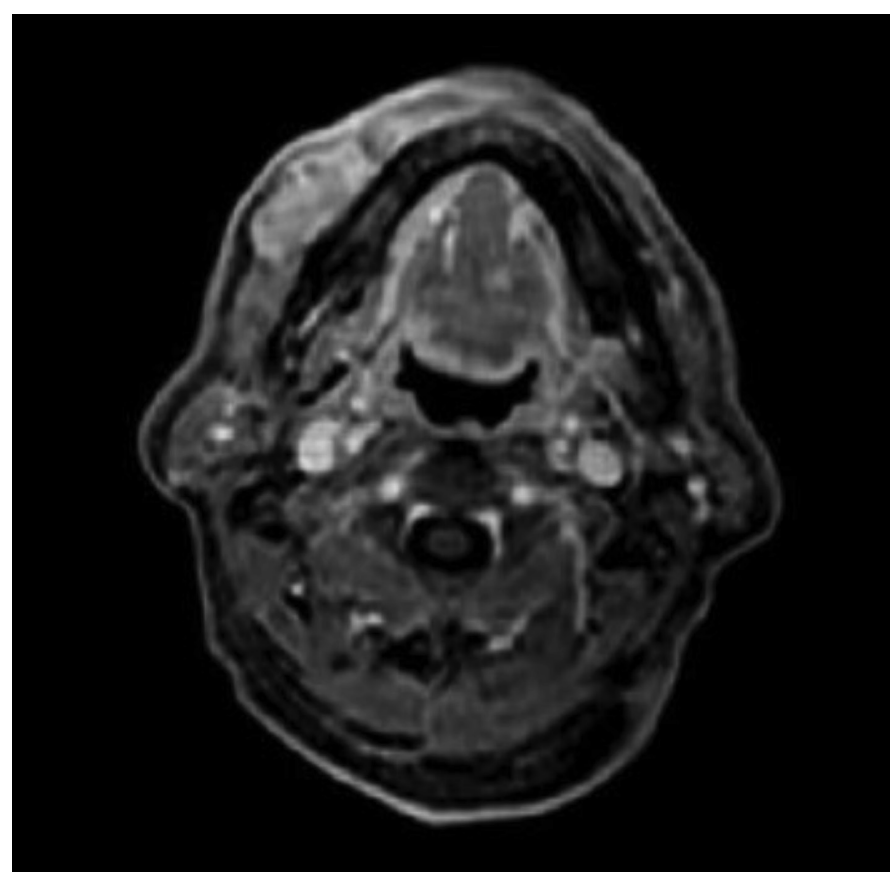

Figure 2. The lesion showed homogeneous contrast enhancement on contrast series

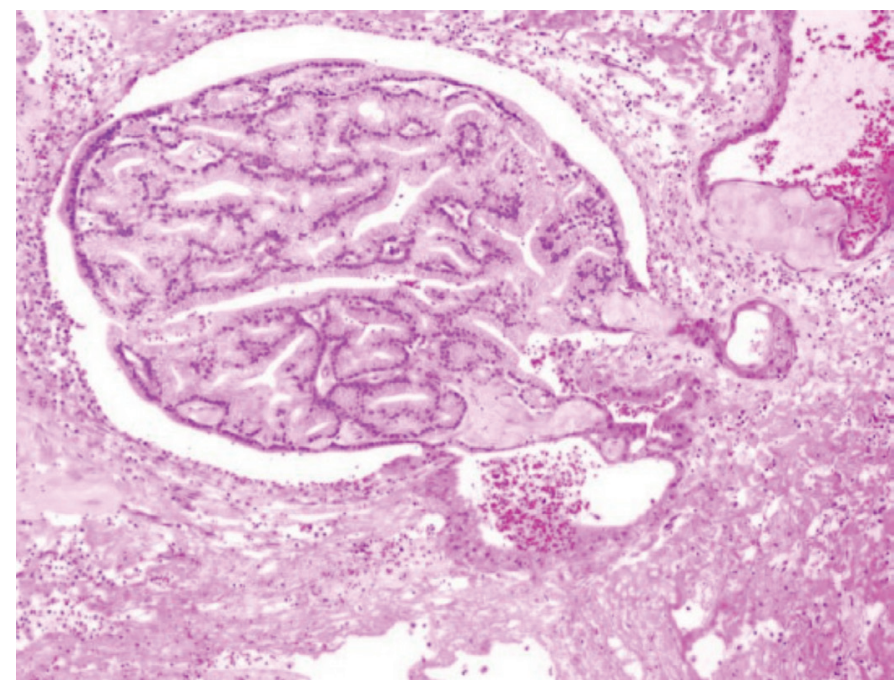

Figure 3. (Haematoxylin and eosin, x100). Cystic space is lined by a double row of cuboidal epithelium. A papillary growth protrudes into the lumina 
literature and reported that with their 3 cases, slightly over 40 cases of ductal papilloma have been reported to date.

The minor salivary glands are more frequently involved than are the major glands. The locations of the reviewed cases by Brannon et al. (4) were as follows: the upper lip (6 cases), the lower lip (6 cases), lip location-not otherwise specified (1 case), the buccal mucosa (7 cases), the soft palate (2 cases), the hard palate (1 case), palate-location not otherwise specified (3 cases), ventral tongue (1 case), and oral cavity-location not otherwise specified (1 case). Major gland involvement has also been recorded, with 4 cases in the parotid gland, 3 in the submandibular gland, and 2 in the sublingual gland.

After the review of the cases by Brannon et al. (4), 2 cases of minor salivary glands, located in the sublingual region and a case located in the parotid gland, were reported (5-7).

Age range was found to be 29 to 77 years, with a mean of 63 . It was seldom reported in children (6).

Most of the authors in medical literature compromised on the fact that the histogenesis of these lesions as originating from the salivary gland duct epithelium-most likely the excretory duct. Immunohistochemical studies have pointed out an origin in ductal luminal cells ductal epithelium, and excretory duct epithelium $(4,8)$.

There are several reported cases of malignancy that share a similar morphologic pattern with intraductal papillomas. The differences are that they have atypical cellular features and a high K-67 level $(9,10)$.

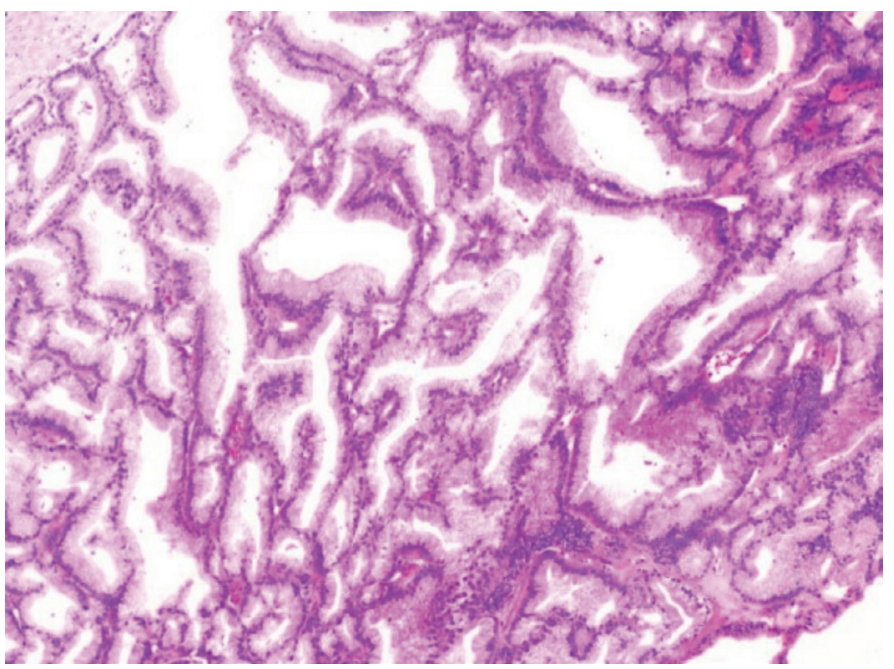

Figure 4. (Haematoxylin and eosin, $x 400$ ). Each papilla, with a branching and anastomosing pattern, was composed of double-layered columnar epithelial cells. The nuclei of the cells were basally located, and they had a monotonous appearance
The intraductal papilloma usually occurs in adults and is usually located in the minor salivary glands. Lower lip and mandibular vestibule are the most frequent locations. The lesion usually appears as an asymptomatic submucosal nodule (1-3).

The majority of the patients are in their sixth or seventh decades, with a mean age of 63 years (1-3). Tumor size ranges from 0.5 to $2.0 \mathrm{~cm}(1-3)$.

Before making a diagnosis of intraductal papilloma, it is essential to rule out several papillary and cystic salivary gland tumors, including papillary cystadenoma (1-3), low-grade cribriform cystadenocarcinoma (LGCCC) (11), and the papillary cystic variant of acinic cell carcinoma (12). The histologic differential diagnosis for intraductal papilloma, take place between 3 lesions: papillary cystadenoma, salivary gland duct blockage phenomenon, and inverted ductal papilloma (3).

Papillary cystadenoma is a multicystic lesion composed of multiple papillary structures consisting of different epithelial cell types, which take part in the differentiation of intraductal papilloma that is a unicystic intraluminal papillary proliferation of neoplastic ductal epithelium (1).

A salivary gland duct may enlarge and form a cyst because of inflammation and obstruction. During this process, epithelial hyperplasia can occur and may form intraluminal papillary structures mimicking intraductal papilloma. The non-papillary lining may contain areas of stratified squamous epithelium. There is usually chronic inflammation, fibrosis, and acinar atrophy around the salivary glands near to the lesion (3).

Inverted ductal papilloma is lined by epidermoid cells, which is the most important different part of this lesion helps distinguish from intraductal papilloma. Inverted ductal papilloma is located near to the mucosal surface, whereas intraductal papilloma is found at deeper levels $(13,14)$.

LGCCC is characterized by multiple ductal in situ lesions. The ductal lesions have micropapillary, tufted, and plaque-like intraluminal projections, rather than frank papillary projections with fibrovascular cores protruding into a cystically dilated duct (11).

Acinic cell carcinomas rarely show prominent papillary and cystic structures. A variant of acinic cell carcinoma, called "papillary-cystic variant of acinic cell carcinoma" has a delicate fibrovascular core, and should be kept in mind in the differential diagnosis. Lack of acinar differentiation in ductal papilloma helps to exclude the possibility of acinic cell carcinoma (12). 
Despite the benign nature of the lesion, surgical resection is necessary. Malignant transformation can occur in intraductal papilloma, which is also architecturally similar to the benign counterpart, accompanied by cytological atypia, intraductal extension, microinvasion, and lymph node metastases (9). Therefore resection of the tumor with an adequate safety margin in our case was done.

\section{CONCLUSION}

In conclusion, intraductal papilloma is a rare entity in salivary glands that should be kept in mind and should be excised in order to rule out the suspicion of malignancy.

\section{Ethics}

Informed Consent: The patient was operated in Maltepe University Hospital and the informed consent was received before the operation.

Peer-review: Internally peer-reviewed.

\section{Authorship Contributions}

Concept: Ö.Y., Y.P., G.A., C.V., G.K., D.D.A., Design: Ö.Y., Y.P., G.A., C..V., G.K., D.D.A., Data Collection or Processing: D.D.A., Y.P., C..V., G.A., Analysis or Interpretation: Ö.Y., G.K., Literature Search: Ö.Y., G.K., D.D.A., Writing: D.D.A., Ö.Y.

Conflict of Interest: No conflict of interest was declared by the authors.

Financial Disclosure: The authors declared that this study received no financial support.

\section{REFERENCES}

1. Eveson JW, Nagao T (2007). Diseases of the Salivary Glands. In: Barnes L (ed). Surgical Pathology of The Head And Neck, 3rd edn. Informa Healthcare USA Inc, New York, pp 475-646.
2. Di Palma S., Simpson RHW (2006). Major and Minor Salivary Glands. In: Cardesa A, Slootweg PJ (eds). Pathology of The Head And Neck. 1st edn. Springer-Verlag, pp 132-64.

3. Gnepp RG (2002) Salivary Gland Pathology in: Gnepp RG (ed). Oral and Maxillofacial Pathology, 2nd edn. Saunders Elsevier, Philadelphia, pp 389-436.

4. Brannon RB, Sciubba JJ, Giulani M. Ductal papillomas of salivary gland origin: a report of 19 cases and a review of the literature. Oral Surg Oral Med Oral Pathol Oral Radiol Endod 2001;92:68-77.

5. Aikawa T, Kishino M, Masuda T, Isomura ET, Tanaka S, Namikawa M, et al. Intraductal papilloma arising from sublingual minor salivary gland: case report and immunohistochemical study. Oral Surg Oral Med Oral Pathol Oral Radiol Endod 2009;107:e34-7.

6. Noseri H, Erden T, Toros S, Habesoglu M, Egeli E, Aker F, et al. Intraductal papilloma of the parotid gland in a child. Eur Arch Otorhinolaryngol 2007;264:1385-6.

7. Ramaswamy P, Khaitan T, Anuradha A, Kumar BP, Sudhakar S. Intraductal Papilloma: Atypical Presentation. Case Rep Dent 2013;2013:652728.

8. Ishikawa T, Imada S, ljuhin N. Intraductal papilloma of the anterior lingual salivary gland. Case report and immunohistochemical study. Int J Oral Maxillofac Surg 1993;22:116-7.

9. Nagao T, Sugano I, Matsuzaki O, Hara H, Kondo $\mathrm{Y}$, Nagao K, et al. Intraductal papillary tumors of the major salivary glands: case reports of benign and malignant variants. Arch Pathol Lab Med 2000;124:291-5.

10. Shiotani A, Kawaura M, Tanaka Y, Fukuda H, Kanzaki J. Papillary adenocarcinoma possibly arising from an intraductal papilloma of the parotid gland. ORL J Otorhinolaryngol Relat Spec 1994;56:112-5.

11. Kuo Y], Weinreb I, Perez-Ordonez B. Low-grade salivary duct carcinoma or low-grade intraductal carcinoma? Review of the literature. Head Neck Pathol 2013;7 Suppl 1:S59-67.

12. Khan S, Pujani M, Hassan MJ , Jetley S. Papillary cystic variant of acinic cell carcinoma presenting as parotid tail tumor. Int J Appl Basic Med Res 2015;5:139-41.

13. Reis de Sá Silva, Costa FE, Vizcaíno Vázquez JR. Sialadenoma Papilliferum with Inverted Pattern in a Young Patient: A Case Report. Am J Case Rep 2015;28:663-6.

14. Sala-Pérez S, España-Tost A, Vidal-Bel A, Gay-Escoda C. Inverted ductal papilloma of the oral cavity secondary to lower lip trauma. A case report and literature review. J Clin Exp Dent 2013;5:e112-6. 